\title{
EMERGENT LEADERSHIP: IS E-LEADERSHIP IMPORTANCE IN THE QUALITY OF VIRTUAL EDUCATION?
}

\section{(LIDERAZGOS EMERGENTES: ¿ES IMPORTANTE EL E-LIDERAZGO EN LA CALIDAD DE LA EDUCACIÓN VIRTUAL?)}

\author{
Ingrid Garcia \\ Autonomus University of Madrid, Spain
}

\begin{abstract}
In latest years, school management systems have become an important tool for effective e-leader. These systems emphasize an information flow and e-communication between all the organizations. The purpose of this study was to emphasize up its main objective how new technologies can assist teachers. The use of information and communication technology in educational settings in the future of teaching is examined with regard to new functions and roles of teachers in coming university distance scenarios. The specific case of the virtual leader and mentor is studied. The article defines and explores the relatively new leadership paradigm of e-leadership that has arisen in little more than a decade. Special attention is given to the following topics: The first section is to develop a theoretical framework to improve understanding of this new form of work related to tutors, the leader and distributed leadership in the virtual environment; also we review literature to build a comprehensive understanding of what constitute e- leadership in organizations. The second section discusses the main strengths and skills of the virtual leader and their importance in the management of education at a distance. We focus on delineating the dimensions of a typology to characterize different types of virtual teams; the dimensions are then used to draw leadership implications. Finally, the general research question guiding this investigation was what will bring about rea progress and provide leadership to the virtual or distance learning? We live in the e-generation.
\end{abstract}

Keywords: distance education, leadership, virtual environments, web based instruction.

\section{RESUMEN}

En últimos años, los sistemas de gestión de las escuelas se han convertido en una herramienta importante para la eficacia de e-líder. Estos sistemas enfatizan un flujo de información y la e-comunicación entre todos los departamentos de las organizaciones. El propósito de este estudio es el de enfatizar cómo las nuevas tecnologías pueden ayudar a los maestros(as). Se examinan también el uso de la información y la comunicación, en los centros educativos, el futuro de la enseñanza con respecto a las nuevas funciones y roles de los maestros(as) en los próximos escenarios de la educación a distancia. Se estudia específicamente 
el e-líder o e-mentor. El artículo define y analiza un nuevo paradigma emergente de liderazgo, el e-liderazgo, que ha surgido hace más de una década. Se presta una especial atención a los siguientes temas: La primera sección es una extensa revisión del marco teórico, con el fin de comprender esta nueva forma de trabajo relacionado con los tutores y el líder en el entorno virtual; también revisamos la literatura para construir una comprensión global de lo que constituye el e-liderazgo en las organizaciones. La segunda sección analiza las principales fortalezas y habilidades del e-líder y su importancia en la gestión de la educación a distancia. Nos centramos en la delimitación de las dimensiones para caracterizar los diferentes tipos de equipos virtuales. Por último, la pregunta general que orienta esta investigación es si: ¿El liderazgo virtual traerá consigo un progreso real para la e-educación? Vivimos en la e-generación.

Palabras clave: educación a distancia, liderazgo, entornos virtuales, instrucción basada en la web.

The e-leadership have been studied, review and conceptualization, during the late 1990's, with the rapid rise in advanced information technology (AIT) such as the Internet, e-mail, video conferencing, virtual teams. By that time, there were a number of authors beginning to examine how AIT would transform how organizations organize their work and the implications for leadership in those organizations.

We have to be clear about that much of this discussion fell under the broad label of "virtual" with authors at that time speculating how such technology might impact how leadership was practiced and investigated.

A decade later, the e-leadership have been re-examine as a theory, research, and practice have evolved with respect no only about the work also its implications for the way e-leadership functions.

As most of organizations concepts have been changed, forms of employment, which until recently were seen as stable and secure. In these particular case, Education is an organized process, and becomes more organized with the passage of time, developing into more complex systems which move in more specialized or technical directions. Faced with these emerging new styles and theories, leadership makes a greater difference in the quality and performance of the school. Virtual and distance education are not exempt from this principle.

On the other hand, holistic school curricula that will need to be versatile and cosmopolitan while fitting into the current context of academic standards. The new professional arising to meet these challenges should not only direct this change but work to instill an unwavering humanism with modern values. This novel contribution reflects the characteristics of the new role of teachers and particularly those of one of their core functions: tutorial action. A new role for the professoriate in the emerging millennium has been recognized and encouraged, especially as technology-assisted 
instruction has proliferated and changed the way teachers and students interact (Hallinger \& Snidvongs, 2005).

In the past, tutorial was presented as a complement to the instructor's teaching load. It could be used for the timely resolution of questions contained in the agenda, before the review, to improve topics or personal difficulties, and so on. A mentor can be defined as a veteran teacher assigned to a new teacher; veteran here refers to a teacher that is not in his or her first year of teaching. However, the number of years of experience is not necessarily a fixed variable. Within the large spectrum of teaching duties, new tasks and challenges are being added, and tutoring is increasingly being seen as an area planned by the teacher. This may include activities specific to the field, strategic approaches, methodology, objectives, and so on. The existing paradigm is shown to be lacking when mentoring is used in an ad hoc approach without proper planning (Carreno, 2008-2009). These thoughts lead us to the following question: What will bring real progress and provide leadership for virtual and long-distance learning? (McFarlane, 2011).

\section{LITERATURE REVIEW}

\section{The university e-Tutor and e-tutoring}

A 1989 record of a virtual tutor for the Office of Technology Assessment of the United States Congress states that: "the key to the success of distance learning is the guardian. If the coach is good, the technology becomes almost transparent. On the contrary, no technology can overcome a poor tutorial" (Clark, 2000). Here we must differentiate between teachers and virtual guardians.

The former design the course and content, create materials, and plan and develop the methodology and activities. Virtual tutors are the mediators between teacher and student and between content and learning; also virtual tutor must be well versed in a large number of concepts including: Pedagogical technology, communication, ethics, and the organization of ideas and groups. The virtual tutor and the trainer should be extensively trained in these fields and be aware of the impact they may have on the students or participants.

E-tutoring can be defined as teaching, support, management and assessment of students on programmers of study that involve a significant use of online technologies. Thus, at first glance, e-tutoring is only different to tutoring in terms of the involvement of technology. Herein, however, are contained vital differences in terms of time, distance and the specific technologies adopted, and these all have implications for teaching staff. The capabilities required can be quite different to face-to-face teaching both in terms of integrating appropriate forms of technology into learning activities and in managing and supporting students' learning online (Carreno, 2011). 


\section{Theoretical considerations for examining e-leadership}

The communication in this study defines and explores the relatively new leadership paradigm of e-leadership that has arisen in little more than a decade. In order to present this resume we show it in Table 1. This article presents existing literature on e-leadership relating to universities schools systems. This researcher primarily utilized the following databases: EBSCO Online, Emerald Management XTRA, Ingenta Connect, and Science Direct. The following major key words, phrases, and their variants were used in researching the databases: e-leadership, virtual leadership. Table 1 presents e-leadership concepts since 1993 to 2010 relating to e-learning.

Table 1.

\section{E-leadership concepts}

Authors, year

Trist, 1950, 1993; Klein \& Hirschheim. 1983; Okamura \& Fujimoto, 1995; Orlikowski \& Okamura, 1999.

Orlikowski et al. (1995)

Avolio et al. (2000)

\section{E-leadership concept}

E-leadership builds on the socio-technical systems approach (Trist, 1950, 1993), according to which organizational effectiveness is determined by how well the social and technical systems are designed to align with each other and the external environment. A main difference between the earlier focus on socio technical systems and our research of e-leadership is that we believe much less independence exists between social and technical systems than described sociotechnical systems are correlative.

Described the recursive relationship between AIT and the context in which it IS used in their work on "technology-use mediation." Which they define as a deliberate organizationally sanctioned intervention to help adapt new technology within context and to modify the context to accommodate technology use.

Reviewed existing literature to reach a broad understanding of what constitutes e-leadership in organizations. It is the first time of the use of the term e-leadership: -We chose the term e-leadership to incorporate the new emerging context for examining leadership. The authors defined e-leadership as - a social influence process mediated by AIT (advanced information technology) to produce a change in attitudes, feelings, thinking, behavior, and/or performance with individuals, groups, and/or organizations.

They also asserted that e-leadership - can occur at any hierarchical level in an organization, involving both one-to-one as well as oneto-many interactions over electronic media. The authors used the Adaptive Structuration Theory (AST) to study how technology and leadership impact each other-more specifically, how technology impacts leadership and is itself changed by leadership. AST is based on the theory that -human action is guided by structures, which are defined as rules and resources that serve as templates for planning and accomplishing tasks. 
Authors, year

\begin{tabular}{|c|c|}
\hline & $\begin{array}{l}\text { The authors 'research indicated that technology creates organization } \\
\text { structures of which leadership is a part, but at the same time, these } \\
\text { organization structures continue to be transformed by the impact of } \\
\text { leadership and technology. Leadership and technology, therefore, } \\
\text { enjoy a recursive relationship, each affecting and at the same time } \\
\text { being affected by the other; each transforming and being transformed } \\
\text { by the other. }\end{array}$ \\
\hline $\begin{array}{l}\text { Pulley and Sessa } \\
\text { (2001) }\end{array}$ & $\begin{array}{l}\text { Explored the impact of digital technology on leadership and identified } \\
\text { e-leadership as a complex challenge that is defined by five key } \\
\text { paradoxes: (a) swift and mindful; (b) individual and community; } \\
\text { (c) top-down and grass-roots; (d) details and big picture; and (e) } \\
\text { flexible and steady. In order for people to overcome the challenge of } \\
\text { e-leadership, people in organizations must make sense together of the } \\
\text { challenges facing them, and participate in leadership at every level. } \\
\text { According to the authors, perhaps the greatest e-leadership challenge } \\
\text { is how to make individuals work collectively to create a culture that } \\
\text { allows all the voices of leadership to be heard. }\end{array}$ \\
\hline $\begin{array}{l}\text { Antonakis and } \\
\text { Atwater (2002) }\end{array}$ & $\begin{array}{l}\text { Noted that the concept of leader distance has been subsumed } \\
\text { in a number of leadership theories. This article, amongst other } \\
\text { goals, discussed leader distance: how distance is implicated in the } \\
\text { legitimization of a leader; and, how distance affects leader outcomes. } \\
\text { The authors reviewed available literature and demonstrate that } \\
\text { an understanding of leader-follower distance is vital to the task } \\
\text { of untangling the dynamics of the leadership influencing process. } \\
\text { Distance is physical distance, but also social distance. Both types of } \\
\text { distance are studies, with physical distance resulting in the need for } \\
\text { virtual leadership. }\end{array}$ \\
\hline $\begin{array}{l}\text { Zaccaro and Bader } \\
(2003)\end{array}$ & $\begin{array}{l}\text { Noted that today's organizational leader grapples with two interrelated } \\
\text { forces: (a) the increasingly global dispersion of divisions and subunits, } \\
\text { customers, stakeholders, and suppliers of the organization; and (b) - } \\
\text { the exponential explosion in communication technology\| that has led } \\
\text { to - greater frequency of daily interactions with colleagues, coworkers, } \\
\text { subordinates and bosses\| dispersed geographically. The authors } \\
\text { postulated that in view of the rapid technology growth in organizations } \\
\text { and their increasingly global reach, in the near future - e-leadership } \\
\text { will be the routine rather than the exception in our thinking about } \\
\text { what constitutes organizational leadership. }\end{array}$ \\
\hline
\end{tabular}


Authors, year

\begin{tabular}{|c|c|}
\hline $\begin{array}{l}\text { Hamilton and } \\
\text { Scandura (2003) }\end{array}$ & $\begin{array}{l}\text { Examined the concept of e-mentoring in a digital world as a necessary } \\
\text { corollary to e-leadership; identified potential benefits and challenges; } \\
\text { and discussed the opportunity to extend technology to address } \\
\text { relationship building and nurturing. Underscoring the importance of } \\
\text { mentoring in general, the authors quoted other scholars to justify that } \\
\text { in the race to the top, mentoring can make a difference. They discussed } \\
\text { the barriers to e-mentoring, such as organizational barriers, individual } \\
\text { barriers, interpersonal barriers, and the changing nature of work. }\end{array}$ \\
\hline & $\begin{array}{l}\text { The authors explored the e-mentoring dimensions defined by functions } \\
\text { and phases. Technology is a critical component of e-mentoring, and } \\
\text { the use of technology can be influenced by situational factors, social } \\
\text { factors and usability factors. Gender, ethnicity, age and personality } \\
\text { also play a part. Integrating technology with the traditional mentoring } \\
\text { models is a challenge that must be overcome. The authors concluded } \\
\text { the e-mentoring is important and extends the use and flexibility of the } \\
\text { traditional mentoring models across time and space. }\end{array}$ \\
\hline Gurr (2004) & $\begin{array}{l}\text { Argued that although e-leadership is a relatively recently emerged } \\
\text { concept with continuing conceptual ambiguity, there are significant } \\
\text { differences between leading traditional organizations and those } \\
\text { that have technology-mediated environments. These environments } \\
\text { appear to require leaders to cope with paradoxes and dilemmas, } \\
\text { and with the associated behavioral complexity. The e-leader must } \\
\text { necessarily establish an appropriate social climate through sustained } \\
\text { communication, and be able to convey exemplary interpersonal } \\
\text { skills through the associated technology. E-leadership also poses } \\
\text { greater emphasis on dispersed leadership. In some situations, such } \\
\text { as anonymous groups, formal leadership may be detrimental to group } \\
\text { performance. Although more research is indeed required, even at this } \\
\text { early stage in the development of e-leadership it is quite apparent that } \\
\text { leadership in technology-mediated environments as a special niche is } \\
\text { important to us. }\end{array}$ \\
\hline $\begin{array}{l}\text { Hambleya, O`Neil, } \\
\text { and Kline (2006) }\end{array}$ & $\begin{array}{l}\text { Explored the new paradigm of work that can now be conducted } \\
\text { anytime, anywhere, in real space or through technology. Leadership } \\
\text { level, and the linguistic quality in one's written communication, it } \\
\text { was found to predict the emergence of transformational leadership in } \\
\text { virtual teams. }\end{array}$ \\
\hline
\end{tabular}




\section{Authors, year}

\begin{tabular}{|l|l|}
\hline Malhotra, & $\begin{array}{l}\text { Studied virtual teams to identify the best leadership practices of } \\
\text { effective leaders of virtual teams. The study collected survey, interview, } \\
\text { and observational data and concluded that successful e-leadership } \\
\text { practices included the ability to: (a) generate and sustain trust through } \\
\text { the utilization of ICT (information and communication technology); } \\
\text { (b) make sure that distributed diversity is both clearly understood as } \\
\text { well as well appreciated; (c) effectively monitor and manage the life } \\
\text { cycles of virtual work; (d) monitor and manage the virtual team's } \\
\text { progress with the use of technology, (e) extend the visibility of virtual } \\
\text { members both within the team as well as outside the company; and (f) } \\
\text { help ensure that individual team members do benefit from the team. }\end{array}$ \\
\hline Carreno, 2008 & $\begin{array}{l}\text { Studied e-mentoring with reference to the virtual leader. The author } \\
\text { focused on the use of information and communication technology in } \\
\text { educational settings. The specific case of the virtual leader and mentor } \\
\text { was examined. The second section discussed the main strengths and } \\
\text { skills of the virtual leader and their importance in the management of } \\
\text { education at a distance. Carreno concluded by formulating a research } \\
\text { question on providing leadership to the virtual or distance learning. }\end{array}$ \\
\hline $\begin{array}{l}\text { Miller, Aqeel- } \\
\text { Alzrooni, and } \\
\text { Campbell (2010) }\end{array}$ & $\begin{array}{l}\text { Presented learning from an interdisciplinary collaborative venture in } \\
\text { the virtual environment between four university teams. The exercise } \\
\text { was designed to enable students to learn experientially the use of a } \\
\text { dynamic social network analysis tools through a variety of projects. } \\
\text { Inter- disciplinary and multi-disciplinary collaborating challenged } \\
\text { the virtual team members to - rapidly and clearly communicate and } \\
\text { demonstrate the value of key principles, processes, and work practices } \\
\text { while negotiating multiple levels of complexity, knowledge cultures, } \\
\text { skills, and capabilities.l The authors proposed a framework for future } \\
\text { collaboration. }\end{array}$ \\
\hline
\end{tabular}

Resource: Carreno (2014). E-mentoring and e-leadership importance in the quality of distance and virtual education Century XXI. 


\section{DISTANCE EDUCATION AND VIRTUAL TEAM}

There is a rich body of literature about educational leadership (Hallinger 2006); but there is considerably less that brings together teaching and learning with ICT and school leadership. Over the past couple of years however, the attributes of an effective 'e-leader' are beginning to be proposed in the literature (Technology Standards for School Administrators (TSSA) (Collaborative 2001). Indeed, research by Dexter (2008) indicates that school leadership plays a central role in achieving technologyrelated outcomes as the following statement illustrates: "our results suggest that a school's technology efforts are seriously threatened unless key administrators become active technology leaders in a school" (p. 74).

Distance education (DE) “... as generally referred to describe a modality that has been practiced through traditional media, long before the emergence of technologies and digital instructional media. These media were based on paper and similar mediums (...) " (Silvio, 2004), virtualization, on the other hand, introduces new elements to education, and can be defined as Silvio (2004, p. 4):

Both a process and a result, occurring simultaneously with application over the digital communications medium of information and knowledge. Specifically, it electronically represents objects and processes that exist in the real world. In the educational context, virtualization can be understood as the representation of objects and processes associated with teaching and learning activities, research, and management as well as objects whose manipulation allows the user to perform various operations through the internet.

Even though some argue that the role of the instructor does not differ significantly from face-to-face education and DE, Perraton who contend that the instructor's temporal and spatial removal from the learner presents the unique requirements for effectively managing both the pedagogical and the logistical elements of instruction (2005). These pedagogical elements include motivating students, promoting relevant learning and facilitating access to course content, engaging the learner in activities and discussions through communication, monitoring learners' progress and adjusting learning opportunities to support learners in areas of difficulty. In this context, DE often takes a learner-centred approach to instruction whereas; the goal is not the transfer of information but the supervision of learners in their pursuit of knowledge (Darabi \& Sikorski, 2006).

Furthermore, much of the responsibility for learning is given to the learner while the instructor acts as a coach, facilitator and tutor. In addition to these pedagogical responsibilities, the DE instructor is often required to manage the complex logistical elements involved in employing technology such as the Internet (e.g., Web-based discussion, Web-based video conference, Web-based chat, email, etc.) and satellite 
communications (Darabi \& Sikorski, 2006). Specifically, the effect that the internet and e-learning have on time and space must be examined. Time and space are the primary dimensions in which the processes of learning and teaching occur. For our purposes, the actors involved in these processes may be in the same place or in different places, yet can interact and communicate at the same time (synchronous or real time) or at different times (asynchronous or deferred ) (Sun et al., 2008) Each subset of educational communication resulting from these combinations presents a specific challenge.

Virtual education is a teaching-learning process based on the principles of active pedagogy (the student should take the responsibility of a frequent and effective participation), with the characteristics of distance education (during all classes, or most of them, the students and the teacher will not meet personally, although this could happen in a virtual space), and with the possibility of synchronous or asynchronous interaction (for example, they can chat with each other in real time using internet services, but also by e-mail or participate in e-groups that are asynchronous technologies that don't require that both are on-line at the same time) (Dias et al., 2014).

\section{Importance of Virtual Team}

The literature has tended to treat virtual teams as a single "ideal" type, yet there are several dimensions or characteristics that vary among and distinguish different types of virtual teams. We focus on four such characteristics - temporal distribution, boundary spanning, lifecycle, and member roles. The concept of a "team" is described as a small number of people with complementary skills who are equally committed to a common purpose, goals, and working approach for which they hold themselves mutually accountable. It is important to notice that getting a group of people to work together (physically) is not enough to make this group of people into a "team". Teams are different from working groups. Virtual teams are created to handle a variety of tasks that range from the simple (e.g., brainstorming) to the complex (e.g., command and control). We will argue that virtual teams need to adopt different characteristics to successfully operate within the constraints that are imposed by the complexity of their collective task.

Literature related to virtual teams revealed a lack of depth in the definitions. Although virtual teamwork is a current topic in the literature on global organizations, it has been problematic to define what 'virtual' means across multiple institutional contexts (García, 2003; Lu et al., 2005). The concept of a "team" is described as a small number of people with complementary skills who are equally committed to a common purpose, goals, and working approach for which they hold themselves mutually accountable (Zenun et al., 2007). It is worth mentioning that virtual teams are often formed to overcome geographical or temporal separations. Virtual teams 
work across boundaries of time and space by utilizing modern computer driven technologies. The term "virtual team" is used to cover a wide range of activities and forms of technology-supported working (Anderson et al., 2007). Virtual teams are comprised of members who are located in more than one physical location. This team trait has fostered extensive use of a variety of forms of computer-mediated communication that enable geographically dispersed members to coordinate their individual efforts and inputs (Peters \& Manz, 2007).

Ebrahim et al. (2009) defined virtual team: "as a group of people and subteams who interact through interdependent tasks guided by common purpose and work across links strengthened by information, communication, and transport technologies". Other definition proposes that virtual teams are: distributed work teams whose members are geographically dispersed and coordinate their work predominantly with electronic information and communication technologies (e-mail, video-conferencing, telephone, etc.) (García, 2003). Also virtual teams are groups of individuals collaborating in the execution of a specific project while geographically and often temporally distributed, possibly anywhere within (and beyond) their parent organization (Johnson et al., 2001).

Powell et al. (2004): "Define virtual teams as groups of geographically, organizationally and/or time dispersed workers brought together by information technologies to accomplish one or more organization tasks".

For Dexter (2008) effective leaders who support teaching and learning with information and communications technologies (ICT) have a good, personal understanding of pedagogy with technologies (how students learn and how ICT can be embedded into teaching and learning). These school leaders display the following attributes concerning the relationships between pedagogies and technologies (figure 1). 
Credibility and authority among their peers;

A futur esperspective;

A global perspective;

Political nous;

A student-centered view of what makes for good learning and good classroom practices;

A good understanding of the likely impacts a cross the school of the ICT decisions they make).

Figure 1. Attributes concerning the relationships between pedagogies and technologies

Soure: (Moyle 2006; Mladenova and Kirkova, 2014)

In addition, these leaders are capable of:

Driving innovation;

Incorporating ICT into their own work;

Conceptualizing preferred futures and how to get there;

Being personally productive with technology;

Using ICT to solve problems;

Engaging with others outside of teaching;

\begin{tabular}{l} 
Having a broad understanding of people's lives outside \\
\hline school; \\
\hline
\end{tabular}

Accepting that they don't know everything but are willing to have a go anyway,

Enjoying a challenge

Figure 2. More attributes concerning the relationships between pedagogies and technologies

Soure: (Moyle 2006; Mladenova and Kirkova, 2014) 


\section{The Distance Leadership Education}

Before the introduction of the role of leadership in distance education it is important to define the term "competency." It is a multidimensional concept Hoffmann defined in numerous ways. While some describe it as observable behaviors or skill sets, others refer to it as standards or quality of performance. Still others define the term as the dimensions of knowledge, skills and abilities, such as personal attributes. Richey et al. define competency as: "a knowledge, skill, or attitude that enables one to effectively perform the activities of a given occupation or function to the standards expected in employment" (2001, p. 31).

To successfully manage anything, there must be people who are willing to take on leadership roles, especially when the thing or concept being managed is an innovation which should be spread in society, while also maintaining a high level of quality. Thus, quality and management are united. A visionary leader is able to act in a way that furthers the mission of an organization- its vision, purpose, objectives and future. The distance education leader guides the organization and its members with their keen understanding of the design, management, leadership and vision of distance education. A virtual leader must possess numerous skills if they are to successfully adhere to the initiatives of distance education. They must be able to negotiate with other members of groups in the educational field. In addition, they must be democratic, in possession of a global vision, and willing and able to work with diverse groups. Above all, they must be a good communicator and have the critical skills necessary to plan, drive, monitor and evaluate the programs and projects of distance education.

With strong leadership, the programs of distance education are able to successfully and efficiently achieve their objectives while remaining responsive to the needs of their beneficiaries and users. The integration of Vision, Knowledge, Design, Management and Leadership is the basis of this approach to the development of distance education. It is necessary to exercise appropriate leadership to ensure a proper quality of distance education. The criteria needed in a virtual education leader can be summarized within four basic areas:

Extensive Knowledge of Distance Education Related Subjects. A leader must be well versed in the evolution and cross-development of distance education, be able to understand terminology used by distance educators, be aware of what it means to work in a virtual environment and have extensive knowledge of understanding of the technology in use.

Experience in the Design of Distance Education. A leader must be familiar with the majority of the important distance education models and understand the structure and design of the courses in virtual and distance education. 
Experience Managing Distance Education. A leader of a team of designers must be able to negotiate and communicate the process of managing distance learning. The components of a policy document must be generated as well as understanding the process to produce a document to formulate a policy for distance education. Finally one must negotiate the process of working with customers and suppliers.

Broad Vision of Distance Education. A leader must possess a visionary approach to distance education, understand the paradigms associated with distance education and the current and future trends of virtual education from a global perspective, and be completely familiar with the characteristics and the development of distance education.

There are three main ideas in these guidelines (Silvio, 2004): Since technology is the basis of distance education the quality of distance education depends largely on the management of technology. With the assistance of technical staff, distance education leaders must assess the educational needs and technological experience of the target population. Distance education must be shaped and developed to meet the needs of all participants, especially students, always considering their values, needs, expectations and aspirations, also it is an innovation and it is possible to manage its diffusion in society in a systematic manner. It is too the functioning of a team of leaders from the same population segment (or other segments), who, like other actors who do not exercise direct leadership, still influence actions, thoughts and feelings and can thus influence the decisions of others in relation to distance education. Finally, a summation of the existing research offers an answer to the next question: What real contribution does leadership provide to distributed, virtual or distance education?

If one starts from the premise that the three dimensions involved in virtual education are in fact distinct (or asynchronous) space-time elements it could be said that the virtual leader should use distributed leadership to promote socialization and its functioning within the group. Innovation is the key to success in the virtual process, arising in the form of new styles and strategies to augment or supplant the basic learning process. The virtual leader must be prepared to implement educational reforms both internally and externally, contributing positively to the effectiveness of the organization, which in this case is education itself. Authority lines should be clear, but ideas should flow among all the participants, and decisions should be made on a group as opposed to individual basis.

Virtual education directly depends on technology, thus virtual leaders must be able to manage the ever-evolving nature of technology while maintaining balance within the group of educators and students. Distributed leadership, seen as a new emergent feature of an interacting network or group of individuals, is a form of action that arises when people work. When the concept of distributed leadership is viewed 
within a network of group interaction, it is seen how technology and virtually can be perfectly adapted to the model. While certain group members may initially possess concentrations of skills, the distributive process itself acts a facilitator by which the group may appropriate these capabilities and use them communally, though this depends on the competency and skill of the virtual leader.

Finally, cooperation, in terms of the globalized individual, accepts differences and diversity and is actively enriched by them. This leaderless-style of leadership is ultimately a community leadership, leading to the emergence of an organizational entity that is, from a holistic or systemic perspective, more than the sum of its constituent parts. Here the two indivisible faces of the singular process appear: the individual and the collective transformation. These processes are fundamentally united because neither can advance without the other, and in recognizing this we must discard the linear logic promoted by the old paradigm which leads us to promote one over the other. The values that guide this change, on both a personal and community level, are emerging everywhere today in the minds and hearts of the members of humanity.

\section{E-LEADERSHIP STRATEGIES}

The most effective style of leadership to ensure and continuously improve the quality of distance education (and the instructional technology that accompanies it) is one that is based on knowledge of the aforementioned variables, concepts and principles. When they are properly combined an effective distance education strategy can be implemented. This should be both a participatory and distributed leadership: participatory because it should facilitate the participation of everyone in decision-making process and the execution of appropriate actions, and distributed because the power and authority should be distributed appropriately to all group members involved in management. Quality management in distance education should be conducted independently of the existence of a formal system for evaluating and monitoring quality. In the absence of such a structured system, the actors involved in the process must reach agreements to establish minimum acceptable standards for use in evaluation and quality management. The exercise of leadership for effective management of the quality of distance education is a complex but not impossible task. It includes, above all, an understanding of the three-dimensionality that distance education operates within, which consists of the dimensions of space, time and virtually.

Based on our findings, we developed some e-leadership strategies to improve working, living, and surviving organizational life. As we can see in Figure 3 these strategies are: 


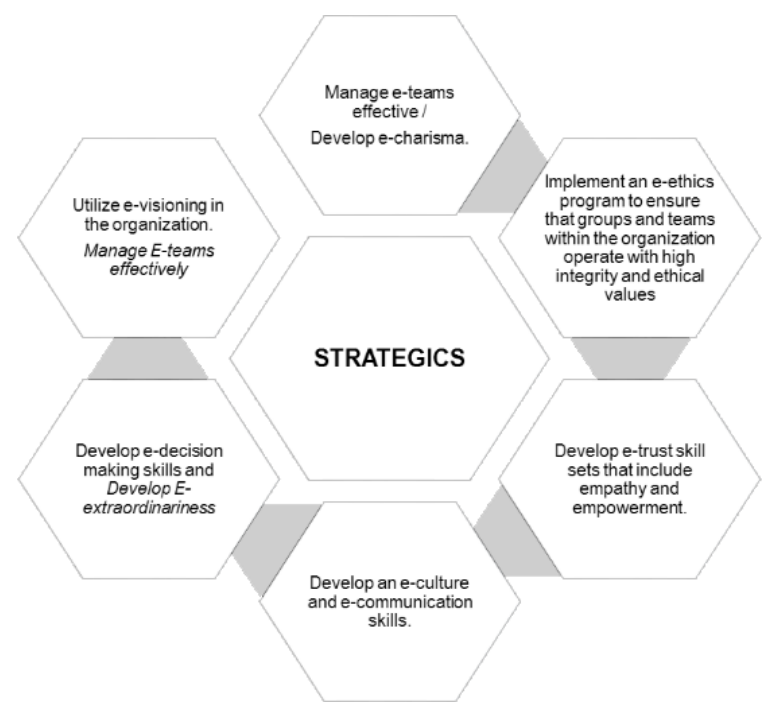

Figure 3. E-leadership strategies to improve working, living, and surviving organizational life

Develop E-charisma. Charisma is a powerful leadership force, but traditionally charisma has depended on personal attributes and force of personality that may not be easily transmitted through the mediating technology. Thus, E-leadership must involve the transformation and transference of charisma through processes such as routinization. This would include rites, rituals, ceremonies and other cultural forms.

Implement an E-ethics program to ensure that groups and teams within the organization operate with high integrity and ethical values. Violations of integrity and ethical standards could promote disaster for the organization. Employees must be educated on integrity and ethical values and a no -tolerance program to indiscretions in this area has to be maintained. Continuous monitoring must be performed, and checks and balances put into place.

Develop E-trustskill sets that include empathy and empowerment. Trust depends on the leader. The leader's impact on followers will depend on levels of trust. Trust at a distance is less well understood than trust in a face-to-face situation. Nevertheless, the leader must develop trusting relationships to achieve organizational success.

Develop an e-culture and e-communication skill. Everyone in the organization will need to buy into the new cultural philosophy for e-leadership to be successful. Develop a culture in which people take pride in each other's accomplishments and 
in which the competence of others is not threatening. Develop E-communication skills include online communication skills. Having good oral communication skills does not mean that the leader will have good online communication skills. Proper training in persuading, negotiating, involvement and direction online will need to be performed to enable employees to communicate effectively.

Develop e-decision making skills and develop e-extraordinaries. Nothing happens without a decision. Leaders make decisions. In an E-environment, leaders require information from all levels of the organization to make decisions. Advanced information technologies, including e-mails, chat rooms, and message boards, are required to support effective decision making. E-leaders must acquire skill sets that enable them to function in the E-environment of advanced information. Also about develop E-extraordinariness. People follow extraordinary people. If leaders perform too many mundane and ordinary tasks they will be perceived as ordinary. In an E- led organization, leaders must delegate much of the administrative detail to organizational members. Thus while e-leaders may return e-mails, they will respond to serious and exceptional requests rather than to routine or trivial communications.

Use e-motivation skills. E-leaders catalyze and facilitate goal achievement. They energize the organization and its members through non-traditional means that call upon technology to assist in unleashing potential and further by providing intrinsic rewards and incentives to accomplish goals.

Utilize e-visioning in the organization and manage E-teams effectively. Leaders focus on the future rather than on the day-to-day details. They tend to be big picture people with highly developed conceptual skills. Leaders must create opportunities for the power of vision at a distance. This will not be easy because technology often limits capabilities to share enthusiasm and energy that are associated with visioning. Managers will rely on e-teams, just as they rely on the dominant coalitions in traditional leadership paradigms. These e-teams will transmit cultural forms such as rites, rituals, and rumors (Malvey \& Hamby, 2004).

\section{METHODOLOGY}

This paper reviews existing literature on e-leadership, attendant concept of virtual teams and important strategies to improve working on virtual teams. The related materials are collected through which this paper provided the chronological order of present content. The materials are mainly concerned with the origins, definitions, challenges and perspective of the concept of the virtual team from various angles: structure, communication, degrees of virtually, multi-cultural issues, trustbuilding, ethical issues, and so on. In fact, this article presents existing literature on e-leadership. This researcher primarily utilized the following databases through the Regent University Library access: ABI/Inform, Business Source Premier, EBSCO 
Online, Emerald Management XTRA, IngentaConnect, and ScienceDirect. The following major key words, phrases, and their variants were used in researching the databases: e-leadership, virtual leadership, distant leadership, leading virtual organizations, leading virtual teams, and leading virtual workforces. About 91 journal articles were ultimately shortlisted for this study and reviewed. The existing body of knowledge thus discovered falls under three categories: e-leadership; virtual teams and workforces; and technology. Finally, the technology that supports e-leadership and virtual teams is briefly discussed.

\section{CONCLUSIONS}

- With time, leadership has evolved along with educational organizations and the process of education itself. Education has moved from a primarily unidirectional and printed form to a medium which includes distance learning and audiovisual integration. Audiovisual teaching has evolved from support training in computer science, to the era of telematics in which we are currently immersed. Today's widely available technology is creating a revolution in the process and dynamic of education.

- In virtual leadership, integration plays a key role throughout the educational process by allowing effective leadership in achieving the goals and objectives and of the programs and projects in distance education. The virtual leader must have the following strengths and skills: extensive knowledge of the subject matter, design experience, management skills, and a broad vision of distance education.

- E-leadership is a new leadership paradigm that requires the leader to achieve these leadership objectives in a computer-mediated manner with virtual teams that are dispersed over space and time, the main medium of communication amongst leader(s) and followers being the electronic conduit supported by computers. What is very different is that the e-leader may never physically meet one or more of the followers. The new paradigm provides a plethora of new opportunities, as well as a number of new challenges and strategies.

- As the nature of work in today's organizations becomes more complex, dynamic, and global, there has been an increasing emphasis on far-flung, distributed, virtual teams as organizing units of work. Despite their growing prevalence, relatively little is known about this new form of work unit.

- Virtual education is a teaching-learning process based on the principles of active pedagogy (the student should take the responsibility of a frequent and effective participation), with the characteristics of distance education (during all classes, or most of them, the students and the teacher will not meet personally, although this could happen in a virtual space), and with the possibility of synchronous or asynchronous interaction (for example, they can chat with each other in real time using internet services, but also by e-mail or participate in e-groups that are 
asynchronous technologies that don't require that both are on-line at the same time).

- After all this studies we can see that e-leadership can be demarcated as a social influence process mediated by information technology to produce a change in attitudes, feelings, thinking, behavior, and/or performance with individuals, groups, and/ or organizations. The fundamental point is that e-leadership takes place in an environment where information technology acts as intermediary. In such a state of affairs, not only may a leader's communication with followers take place via information technology, but the collection and dissemination of information required to support organizational work also takes place via Information Technology. In synthesis the most fundamental bottom line is that e-leadership in due course is not about connecting technology, but about connecting people in the best of the ways.

\section{REFERENCES}

Anderson, A., McEwan, R., Bal, J., \& Carletta, J. (2007). Virtual team meetings: An analysis of communication and context. Computers in Human Behavior, 23(5), 2558-2580.

Clark, R. (2000). Evaluating distance education: Strategies and cautions. Quarterly Review of Distance Education, 1(1), 3-16.

Carreno, I. (2008). E-mentoring and e-leadership importance in the quality of distance and virtual education Century XXI. Paper from m-ICTE 2009: Research, Reflections and Innovations in Integrating ICT in Education. Retrieved from http://www.formatex. org/micte2009/book/728-732.pdf.

Carreno, I. (2009 August) E-tutor and Distance University of XXI Century. In Seminario Internacional RED-U 2-o8: "La acción tutorial en la Universidad del siglo XXI".

Carreno, I. (2011). Management in educational networks: the importance of virtual leader. RELADA-Revista Electrónica de ADA-Madrid, 5(2).

Collaborative, T.S.S.A. (2001). Technology standards for school administrators.
Darabi, A., \& Sikorski, E. (2006). 14 Validated Competencies for Distance Teaching. Distance Education, 27(1), 105-122(18) Publisher: Routledge, part of the Taylor \& Francis Group.

Dexter, S. (2008). Leadership for IT in schools. In International handbook of information technology in primary and secondary education, pp. 543-554. Springer US.

Dias, S., Diniz, J., \& Hadjileontiadis, L. (2014). E-Learning Exequibility in the Information and Knowledge Society. In Towards an Intelligent Learning Management System Under Blended Learning, Springer International Publishing, pp. 3-19.

García Aretio, L. (2003). Comunidades de aprendizaje en entornos virtuales: La comunidad iberoamericana de la CUED. In M. Barajas (Coord.). La tecnología educativa en la educación superior, (pp. 171-199). Madrid: McGraw-Hill.

Hallinger, P. (2006). Leading educational change: Reflections on the practice of instructional and transformational leadership. Cambridge Journal of Education, 33(3), 329-352. 
Hallinger, P., \& Snidvongs, K. (2005). Adding value to school leadership and management. A review of trends in the development of managers in the education and business sectors. Nottingham, England: National College for School Leadership. Retrieved from http://www.ncsl.org.uk/media/1CA/77/ adding-value-to-school-leadership-andmanagement.pdf

Johnson, P., Heimann, V., \& O’Neill, K. (2001). The "wonderland" of virtual teams. Journal of Workplace Learning, 13(1), 24-30.

Lu, M., Watson-Manheim, M., Chudoba, K., \& Wynn, E. (2005). Virtuality and Team Performance: Understanding the Impact of Variety of Practices. Journal of Global Information Technology Management, 9(1).

McFarlane, D. A. (2011). The leadership roles of distance learning administrators (DLAs) in increasing educational value and quality perceptions. Online Journal of Distance Learning Administration, 14(4).

Malvey, D., \& Hamby, E. (2004). E-Leadership: An Investigational Study of a New 21 st Century Leadership Phenomenon-Organizational Strategies for Transitioning to E-Leadership Systems. Association on Employment Practices and Principles, 169.

Mladenova, M. \& Kirkova, D. (2014). Role of Student Interaction Interface in Web-
Based Distance Learning. In ACHI 2014 , The Seventh International Conference on Advances in Computer-Human Interactions, pp. 307-312.

Moyle, K. (2006). Leadership and learning with ICT: Voices from the profession. Teaching Australia-Australian Institute for Teaching and School Leadership.

Peters, L., \& Manz, C. (2007). Identifying antecedents of virtual team collaboration. Team Performance Management, 13(3/4), 117-129.

Silvio, J. (2004). Towards the articulation of learning and non-virtual. Conference offered at the 3 rd International Congress on University Teaching and Innovation. June 30 to July 2, 2004. Gerona, Spain.

Richey, R., Fields, D., \& Foxon, M. (2001). Instructional design competencies: The standards (No. IR-111). Syracuse, NY: ERIC Clearinghouse on Information \& Technology.

Sun, P., Tsai, R., Finger, G., Chen, Y., \& Yeh, D. (2008). What drives a successful e-Learning? An empirical investigation of the critical factors influencing learner satisfaction. Computers \& Education, 50(4), 1183-1202.

Zenun, M., Loureiro, G., \& Araujo, C. (2007). The Effects of Teams' Co-location on Project Performance. In Complex Systems Concurrent Engineering, London: Springer, 717-726. 


\section{PERFIL ACADÉMICO Y PROFESIONAL DE LA AUTORA}

Ingrid del Valle García Carreño. Doctoranda en Ciencias de la Educación por la Universidad Autónoma de Madrid, España. Magister en Administración de Empresas por la Universidad Católica Andrés Bello de Caracas, Venezuela. Especialista en Educación Superior por la Universidad Gran Mariscal de Ayacucho, Puerto Ordaz, Venezuela. Diplomado en el Programa de Desarrollo de Habilidades Docentes, basado en competencias, por el Tecnológico de Monterrey (Beca OEA), México. Profesora universitaria desde el año 1999 al 2005 en varias asignaturas de pregrado y postgrado. Directora de la Universidad Bicentenaria de Aragua en Guayana, Venezuela.

E-mail: ingridvalle.garcia@estudiante.uam.es

DIRECCIÓN DE LA AUTORA

Ingrid del Valle García Carreño

Calle Olite, No. 34, piso 1,1.

28039 Madrid, España.

Fechas de recepción del artículo: 01/07/2014

Fecha de aceptación del artículo: 03/09/2014

\section{Como citar este artículo:}

Valle, I. (2015). Emergent leadership: is e-leadership importance in the quality of virtual education? RIED. Revista Iberoamericana de educación a Distancia, volumen $18, \mathrm{n}^{\mathbf{0}} 1$, pp. 25-44. 